\title{
Combining Active Carbonic Anhydrase with Nanogels: Enzyme Protection and Zinc Sensing
}

\author{
$\mathrm{Di} \mathrm{Si}$ \\ Guochao Nie $\mathbb{D D}^{2-4}$ \\ Tamiika K Hurst' \\ Carol A Fierke' \\ Raoul Kopelman' \\ 'Department of Chemistry, University of \\ Michigan, Ann Arbor, MI, USA; ${ }^{2}$ School of \\ Physics and Telecommunication \\ Engineering, Yulin Normal University, \\ Yulin, People's Republic of China; ${ }^{3} \mathrm{China}$ - \\ Ukraine Joint Research Center for Nano \\ Carbon Black, Yulin, People's Republic of \\ China; ${ }^{4}$ Guangxi Key Laboratory of \\ Agricultural Resources Chemistry and \\ Biotechnology, Yulin, People's Republic of \\ China
}

Correspondence: Guochao Nie School of Physics and Telecommunication Engineering, Yulin Normal University, Yulin, People's Republic of China Email bccu518@ylu.edu.cn

Raoul Kopelman

Department of Chemistry, University of Michigan, 930 N University Avenue, Ann Arbor, MI, USA

Email kopelman@umich.edu
Background: Due to its excellent biocompatibility, the polyacrylamide (PAAm) hydrogel has shown great potential for the immobilization of enzymes used in biomedical applications. The major challenge involved is to preserve, during the immobilization process, both the biological activity and the structural integrity of the enzymes. Here we report, for the first time, a proof-of -concept study for embedding active carbonic anhydrase (CA) into polyacrylamide (PAAm) nanogels. By immobilizing CA in these nanogels, we hope to provide important advantages, such as matrix protection of the CA as well as its targeted delivery, and also for potentially using these nanogels as zinc nano-biosensors, both in-vitro and in-vivo.

Methods and Results: Two methods are reported here for CA immobilization: encapsulation and surface conjugation. In the encapsulation method, the common process was improved, so as to best preserve the $\mathrm{CA}$, by 1) using a novel biofriendly nonionic surfactant system (Span 80/Tween 80/Brij 30) and 2) using an $\mathrm{Al}_{2} \mathrm{O}_{3}$ adsorptive filtration purification procedure. In the surface conjugation method, blank PAAm nanogels were activated by N-hydroxysuccinimide and the CA was cross-linked to the nanogels. The amount of active CA immobilized in the nanoparticles was quantified for both methods. Per $1 \mathrm{~g}$ nanogels, the CA encapsulated nanogels contain $11.3 \mathrm{mg}$ active CA, while the CA conjugated nanogels contain $22.5 \mathrm{mg}$ active CA. Also, the CA conjugated nanoparticles successfully measured free $\mathrm{Zn}^{2+}$ levels in solution, with the $\mathrm{Zn}^{2+}$ dissociation constant determined to be $9 \mathrm{pM}$.

Conclusion: This work demonstrates universal methods for immobilizing highly fragile biomacromolecules inside nanoparticle carriers, while preserving their structural integrity and biological activity. The advantages and limitations are discussed, as well as the potential biomedical applications.

Keywords: PAAm hydrogel, nanogels, nanoparticles, carbonic anhydrase, encapsulation, conjugation, $\mathrm{Zn}^{2+}$

\section{Introduction}

In recent years, hydrogel technology has led to many advanced applications, particularly in biomedical research. Hydrogels are water-laden, three-dimensional polymeric networks, with tailorable chemical and physical properties that are easily achieved by manipulating the chemistry and the manufacturing process. Due to their excellent biocompatibility and potential for engineered biodegradability, hydrogels have been studied extensively for immobilizing enzymes, which has led to numerous applications such as biosensing, environmental and industrial biocatalysis, protein arrays, therapeutics delivery, tissue engineering and more. ${ }^{1-9}$

Strategies of immobilizing enzymes in hydrogel nanoparticles, or nanogels, have already been comprehensively reviewed. ${ }^{1-13}$ Major routes for immobilizing 
enzymes include entrapment via adsorption, ie, encapsulation during the polymerization process, and cross-linking, ie, conjugation. Enzymes can be entrapped in the nanogels via diffusion and adsorption. Physical adsorption is a simple process, during which the active site of the enzyme is usually unaffected. However, the pore size of the nanomatrix must be large enough for the enzymes to diffuse into and be adsorbed, while continuous leaching of the adsorbed enzymes remains a critical issue. Enzymes can also be encapsulated inside the matrix during the polymerization of the nanogels in the presence of the enzymes. The advantage of this approach is that the inert polymer matrix protects the biological cargo from potential environmental damage, such as protease attack, interfacial shearing, acidic or enzymatic conditions (ie, in the gastrointestinal tract). Major drawbacks are: the required complicated experimental procedure, enzyme denaturation during the polymerization process, and low enzyme loading. Alternatively, enzymes can be conjugated onto the surface of nanogels through non-specific or site-specific covalent binding. Unfortunately, in this scenario, the advantage of protecting the biologics by the hydrogel matrix is no longer viable. However, the surface conjugation process is much simpler than the encapsulation process: after the nanogels are synthesized and purified, the enzymes are then covalently linked to the nanogels in solution. The enzyme loading is possibly higher, and the enzyme activity is better retained because the enzymes do not go through the polymerization process to be immobilized. If the nanogel pore size is large enough, enzymes can be covalently linked both inside the nanogels, after physical adsorption, and onto the surface of the nanogels. This approach may thus improve enzyme loading and activity preservation, reduce enzyme leaching, and maintain some protection effects of the matrix.

Aimed at biomedical applications, many proteins and enzymes have been encapsulated within or conjugated onto the hydrogel matrix, as discussed above. The compatibility of the matrix and the enzymes depends on the physicochemical properties of the matrix and on the intrinsic properties of the enzymes. Extensive studies demonstrated that Polyacrylamide (PAAm) hydrogels have excellent biocompatibility with respect to many proteins and enzymes. ${ }^{14-23}$ Notably, PAAm biosensors encapsulating glucose oxidase, ${ }^{17}$ DsRed, ${ }^{18}$ horseradish peroxidase, ${ }^{19}$ phosphate sensing protein, ${ }^{20}$ and human serum albumin ${ }^{21}$ have become promising tools for intracellular sensing. Moreover, proteins and enzymes are readily conjugated onto PAAm nanogels. The latter approach has been demonstrated by attaching cellpenetrating peptides or tumour homing peptides onto PAAm nanogels for in vitro and in vivo targeted delivery. $^{22}$ Both encapsulation and conjugation approaches are investigated in this work, combining a model protein, carbonic anhydrase, with PAAm nanogels.

The metalloenzyme, carbonic anhydrase (CA), which was discovered in red blood cells, catalyses the reversible hydration of $\mathrm{CO}_{2}$ to $\mathrm{HCO}_{3}{ }^{-}$. It is a well-suited protein to serve as a model for studies in biophysics, bioanalysis, and protein stability. Wild type CA is inexpensive and widely available. It is relatively easy to handle, due to its excellent stability under standard laboratory conditions. Also, the structure of CA and its active site, its catalytic activity, and the mechanism of its inhibition by the binding of ligands, are well-understood. ${ }^{24}$

It is well known that wild type CA comprises a catalytic $\mathrm{Zn}^{2+}$ ion at its active site. ${ }^{24}$ The presence of the catalytic $\mathrm{Zn}^{2+}$ cofactor in the active site is the key to the enzyme's stability, catalytic activity, as well as to its inhibitor binding. CA behaves not only as a hydratase/ anhydrase but also as an esterase. The esterase activity of $\mathrm{CA}$, also an indication of its stability, is often measured by using $p$-nitrophenyl acetate ( $p$ NPA) as the substrate. Meanwhile, the mechanism of inhibition of CA by ligands is simple and well-studied. Aryl sulfonamides are the most important class of CA inhibitors. The $\mathrm{SO}_{2} \mathrm{NH}_{2}$ moiety binds to the $\mathrm{Zn}^{2+}$ ion by displacing the zinc-bound water, and thus directly coordinates the $\mathrm{Zn}^{2+}$ to the $\mathrm{CA}$ active site. $^{24}$

Fierke and Thompson have extensively studied wildtype human CA II and its mutants for intracellular $\mathrm{Zn}^{2+}$ sensing. ${ }^{25-31}$ The $\mathrm{Zn}^{2+}$ binding dissociation constant of wild-type human CA II was determined to be $\sim 1 \mathrm{pM}$ at $p \mathrm{H} 7 .^{30}$ Free or readily exchangeable $\mathrm{Zn}^{2+}$ in the cytosol has also been determined to be at the picomolar level. ${ }^{32-34}$ Many fluorescent aryl sulfonamides, with various structural and fluorescent properties, have been developed for CA-based $\mathrm{Zn}^{2+}$ sensing. For example, Dapoxyl sulfonamide (DPS) binds, with high affinity, to holo-CA, the complete form of CA with its cofactor $\mathrm{Zn}^{2+}$ present at the active site. This binding leads to an $80 \mathrm{~nm}$ blue-shift of its emission and a 1000-fold increase in its quantum yield (Figure 1), compared to the emission of free CA in solution. ${ }^{26}$ 


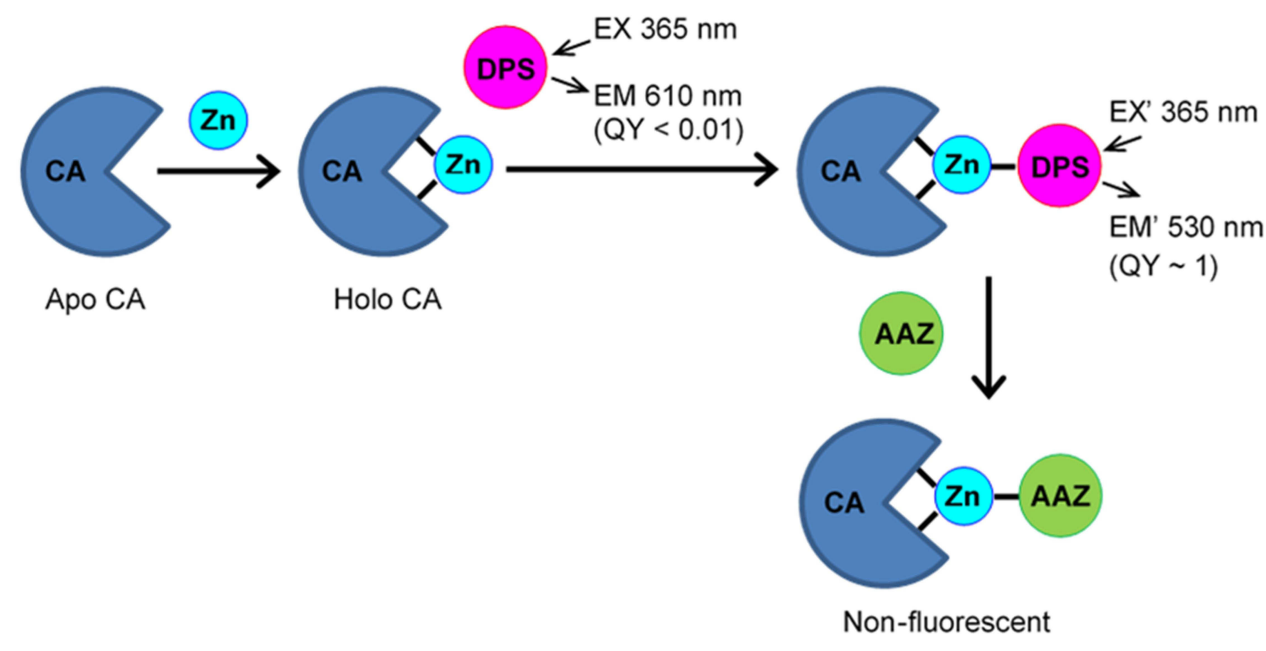

Figure I The CA sensing mechanism for $\mathrm{Zn}^{2+}$. The formation of $\mathrm{Zn}$-bound CA from apo-CA is detected by the binding to CA-Zn ${ }^{2+}$ of the sulfonamide fluorophore, Dapoxyl sulfonamide (DPS), which induces a large shift in the DPS fluorescence. The background fluorescence of the unbound DPS is measured by the addition of Acetazolamide (AAZ), which binds to CA with a tighter affinity, forming a non-fluorescent complex.

Due to its excellent ability to accelerate the hydration of $\mathrm{CO}_{2}$, many studies have utilized $\mathrm{CA}$ for biomimetic carbon sequestration. ${ }^{35}$ Immobilizing CA on various supports has been used to improve its stability and reusability for $\mathrm{CO}_{2}$ capture, among which a few attempts have successfully immobilized $\mathrm{CA}$ in a hydrogel network. For example, CA-liposome conjugates ${ }^{36}$ and metal-organic hybrid nanocomposites ${ }^{37,38}$ have been reported to be embedded into hydrogel beads and membranes during the polymerization process. CA was also encapsulated in silk protein hydrogel via a dual crosslinking strategy, which employed a photoinduced dityrosine chemical crosslinking followed by a dehydration-mediated physical crosslinking. ${ }^{39}$ Poly(acrylic acid-co-acrylamide)/hydrotalcite nanocomposite hydrogels were also used to immobilize CA. In this approach, the nanocomposite was first prepared and activated by N-hydroxysuccinimide, and then the CA was immobilized via adsorption and crosslinking. ${ }^{40,41}$

In this work, bovine wild-type CA was immobilized in a PAAm hydrogel nanomatrix by both encapsulation and by surface conjugation. In the encapsulation approach, CA was immobilized inside the nanogels via in situ polymerization. Our goal was to best preserve the biological integrity of CA during the nanogel fabrication and purification, indicated by the enzyme activity and by the ligand binding of the product, CA encapsulated nanogels. To achieve this goal, studies were focused on choosing a biofriendly surfactant system and a biofriendly nanogel separation method. Wild-type bovine $\mathrm{CA}$, rather than CA mutants, was chosen as the template enzyme, due to its relatively robust nature and affordable price. The factors that affect the CA activity during and due to the nanogel preparation are evaluated and discussed. New nanogel fabrication and purification methods were also developed. In particular, the use of nonionic surfactants for stabilizing the water-in-oil microemulsion during the nanogel synthesis, and the use of the $\mathrm{Al}_{2} \mathrm{O}_{3}$ absorptive filtration for nanogel purification, turned out to be the key factors for enhancing the active CA encapsulation.

In the conjugation approach, Sulfosuccinimidyl4-(N-maleimidomethyl) cyclohexane-1-carboxylate (SulfoSMCC) was used as a crosslinker. The amine-reactive N-hydroxysuccinimide (NHS ester) reacts with the primary amines on the PAAm nanogels so as to form stable amide bonds, while the sulfhydryl-reactive maleimide groups react with the sulfhydryl groups on the enzymes to form stable thioether bonds. ${ }^{42}$ The CA activity that was retained in the CA encapsulated and conjugated nanogels was quantified. The ligand binding to the CA embedded in the nanogels was studied. The potential application of these nanogels for measuring free $\mathrm{Zn}^{2+}$ concentrations was evaluated. The advantages and drawbacks of both CA immobilization approaches are discussed.

\section{Materials and Methods}

Bovine CA (Sigma-Aldrich) was used to prepare both the CA encapsulated and CA conjugated PAAm nanogels. This commercial product is a mixture of isoforms, with no purity claim made by the vendor. 


\section{Preparation of CA Encapsulated Nanogels}

The CA encapsulated nanogels were synthesized in a waterin-oil microemulsion system. This microemulsion is a clear, thermodynamically stable, isotropic liquid mixture of hexane, water and surfactants. The aqueous domain is compartmentalized and stabilized by surfactants as nanometer-sized droplets, and these droplets are dispersed in the hexane phase. These nanosized droplets act as nanoreactors to host the polymerization reaction in the presence of $\mathrm{CA}$, resulting in CA-encapsulated nanogels. At the end of the polymerization reaction, the hexane was removed by rotary evaporation, leaving a viscous mass containing nanogel products, surfactants, unreacted monomers and CA. This viscous mass was then purified to remove the surfactants and unreacted materials, and the CA-encapsulated nanogels were freezedried to form a dry powder.

The monomer solution, which is the aqueous phase of the microemulsion, was prepared by first dissolving $43 \mathrm{mg}$

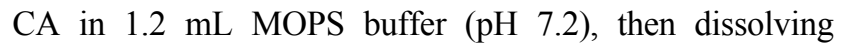
$711 \mathrm{mg}$ acrylamide and $55 \mathrm{mg} \mathrm{N}$-(3-aminopropyl) methacrylamide hydrochloride (APMA) and adding $240 \mu \mathrm{L}$ glycerol dimethacrylate (GDMA) as the last step. The organic phase of the microemulsion was prepared by dissolving various amounts of surfactants in $45 \mathrm{~mL}$ of hexane, and deoxygenated by Argon for $30 \mathrm{~min}$. The monomer solution was then added to the organic phase, and the microemulsion was stirred under Argon throughout the duration of the preparation. To initiate polymerization, $100 \mu \mathrm{L}$ of $20 \%$ (w/ w) ammonium persulfate solution and $100 \mu \mathrm{L}$ N,N,N', $\mathrm{N}^{\prime}$ tetraethylmethylenediamine (TEMED) were added. The solution was stirred at room temperature for two hours so as to assure complete polymerization.

\section{PAAm Matrix Stabilized by AOT and Brij 30}

In the standard PAAm nanogel preparation procedure, AOT (anionic) and Brij 30 (nonionic) are used to stabilize the water-in-oil microemulsion. ${ }^{17}$ The CA encapsulated nanogels (sample $\mathrm{A}$ in Figure 2) were fabricated by using this method, with $1.6 \mathrm{~g}(0.08 \mathrm{M})$ AOT and $3.08 \mathrm{~g}(0.19 \mathrm{M})$ Brij 30 added to the hexane phase, to stabilize the microemulsion, and initially $43 \mathrm{mg}$ CA was added into the reaction mix.

\section{PAAm Matrix Stabilized by Non-lonic Surfactants}

We have successfully used the Hydrophile-Lipophile Balance (HLB) concept to identify suitable multi-surfactant systems, as well as to calculate the composition of each surfactant used in the system. Notably, surfactants are molecules consisting of both hydrophilic and lipophilic groups and HLB is the balance of the size and strength of these two opposing groups. Thus, the HLB value expresses the relative simultaneous attraction of an emulsifier for water and for oil on a scale of 0 to $20 .^{43,44}$ The higher the HLB value, the more

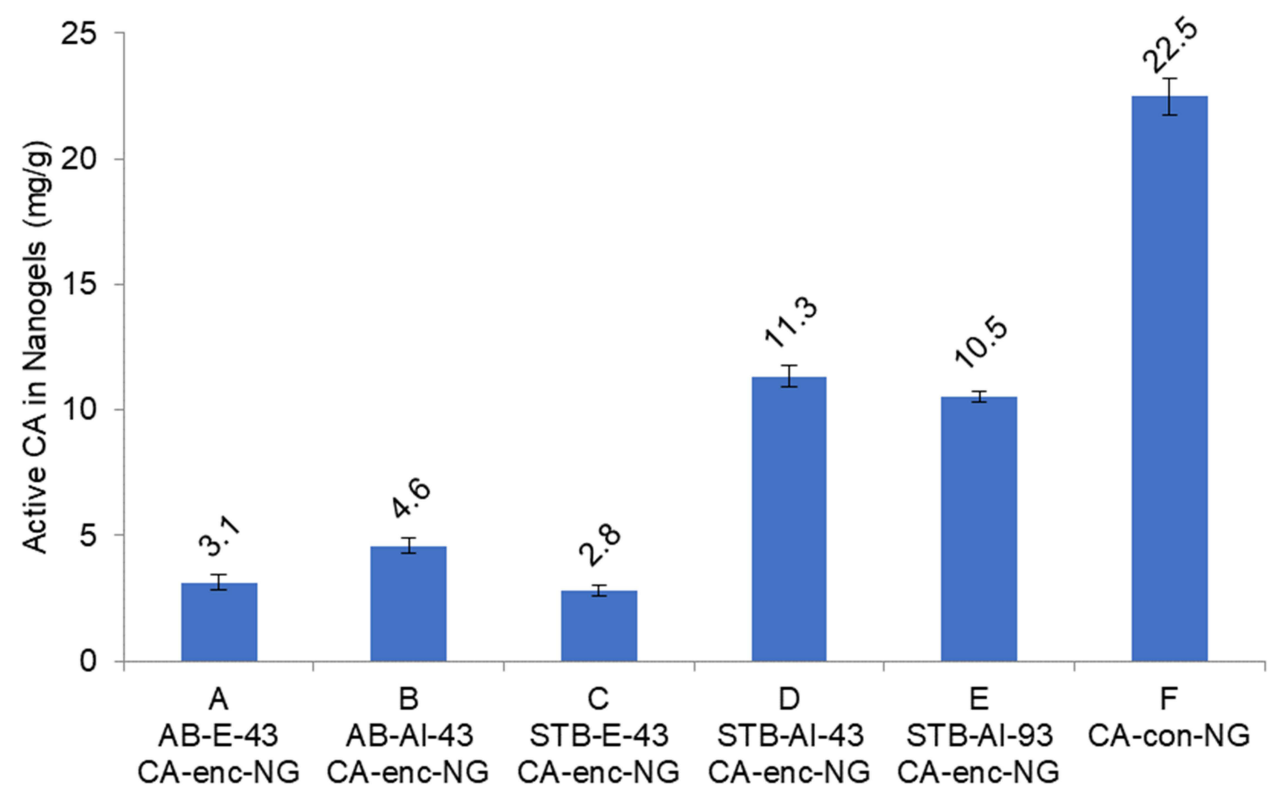

Figure 2 CA activity in CA encapsulated and conjugated PAAm nanogels, measured by the pNPA assay. The names of the samples indicate the nanogel fabrication and separation methods. Sample A-E are CA encapsulated nanogel (CA-enc-NG), and sample F is CA conjugated nanogel (CA-con-NG). "AB" and "STB" denote AOT/Brij 30 and Span 80/ Tween 80/ Brij 30 surfactant systems. "E" and "Al" denote, respectively, ethanol washing and $\mathrm{Al}_{2} \mathrm{O}_{3}$ absorptive filtration. " 43 " and " 93 " denote that 43 mg or $93 \mathrm{mg} \mathrm{CA}$ was initially added in the synthesis of the CA encapsulated nanogels. The data labels indicate the amount (mg) of active CA per Ig nanogels. 
Table I HLB Values of the Surfactants Used in the PAAm Nanogel Synthesis

\begin{tabular}{|l|c|c|c|c|c|c|}
\hline Surfactant & Brij 30 & Tween $\mathbf{8 0}$ & Span 80 & Triton X-100 & PEG 400 & Tergitol \\
\hline HLB value & 9.8 & 15 & 4.3 & 13.5 & 13 & 12.9 \\
\hline
\end{tabular}

Notes: HLB values were obtained from Kunieda and Shinoda ${ }^{43}$ and Griffin $^{44}$ and the Sigma-Aldrich website.

hydrophilic is the molecule; and the lower the HLB value, the more lipophilic is the molecule. The HLB values of the nonionic surfactants used in this work are shown in Table 1. As shown in Table 2, five multi-surfactant systems were used to produce particles, and the amount of each surfactant used in the polymerization reaction is listed. The HLB value of each system in Table 2 was calculated by Equation 1:

$$
H L B_{\text {system }}=\sum\left\{M o l \% \times H L B_{\text {conponent }}\right\}
$$

According to the literature, ${ }^{44}$ and based on our experience, the water-in-oil microemulsion is most stable when its HLB value is about 8 to 10 . Therefore, we have adjusted the composition of each surfactant used in the system, so that the HLB value of each system is within our target value 8 to 10 . System 3 was not successful since CA precipitated during the reaction. Systems 4 and 5 required higher amounts of surfactants for preparing the CA encapsulated nanogels, the amounts of Span 80 and Tween 80 were doubled.

\section{Separation of CA Encapsulated Nanogels}

The choice of particle separation method is also crucial for preserving the CA activity in nanogels. The standard method involves washing the nanogels with large amounts of 95\% ethanol in an Amicon stirred ultrafiltration cell, so as to remove the surfactants and unreacted components. ${ }^{17}$

A new separation method was developed utilizing the $\mathrm{Al}_{2} \mathrm{O}_{3}$ absorptive filtration. In the new method, particles were maintained in the aqueous phase throughout the entire separation process, so that the $\mathrm{CA}$ activity could be best preserved. $50 \mathrm{~g} \mathrm{Al}_{2} \mathrm{O}_{3}$ was immersed in water-saturated hexane for 30 minutes and allowed to stabilize and to cool to room temperature. The polyacrylamide microemulsion was mixed with the stabilized $\mathrm{Al}_{2} \mathrm{O}_{3}$ solution and the mixture was stirred for $30 \mathrm{~min}$ utes while the nanogels in the aqueous phase were adsorbed onto the $\mathrm{Al}_{2} \mathrm{O}_{3}$ surface, leaving most of the surfactants in the hexane phase. The mixture was then vacuum-filtered and the $\mathrm{Al}_{2} \mathrm{O}_{3}$ filtrate was washed eight times with $50 \mathrm{~mL}$ hexane. Then, the residual hexane was completely evaporated, by vacuum filtration or by rotary evaporation, yielding dry $\mathrm{Al}_{2} \mathrm{O}_{3}$ with nanogels adsorbed on the surface. The nanogels were then extracted by washing the $\mathrm{Al}_{2} \mathrm{O}_{3}$ eight times with $50 \mathrm{~mL}$ water. The pooled suspension was centrifuged

Table 2 Multi-Surfactant Systems Used for Nanogel Synthesis

\begin{tabular}{|c|c|c|c|c|c|c|}
\hline System\# & Surfactant & Mass (g) & Mol \% & System HLB & Blank-NG Size (nm) & CA-Enc-NG Size (nm) \\
\hline I & Brij 30 & $8-9$ & 100 & 9.8 & $4 I \pm I I(8$ g Brij 30) & $65 \pm 9(9 \mathrm{~g}$ Brij 30) \\
\hline 2 & $\begin{array}{c}\text { Span } 80 \\
\text { Tween } 80 \\
\text { Brij } 30\end{array}$ & $\begin{array}{c}0.88 \\
2.55 \\
2.6\end{array}$ & $\begin{array}{l}17.9 \\
17 \\
62.7\end{array}$ & 9.70 & $73 \pm 13$ & $84 \pm 16$ \\
\hline 3 & $\begin{array}{l}\text { Span } 80 \\
\text { Tween } 80 \\
\text { I-Hexanol }\end{array}$ & $\begin{array}{l}1.3 \\
1.6 \\
8.6\end{array}$ & $\begin{array}{l}71.4 \\
28.6 \\
\text { N/A }\end{array}$ & 7.36 & $304 \pm 54$ & $\begin{array}{l}\text { N/A } \\
\text { I-hexanol causes } \\
\text { CA precipitation }\end{array}$ \\
\hline 4 & $\begin{array}{l}\text { Span } 80 \\
\text { Tween } 80 \\
\text { PEG } 400\end{array}$ & $\begin{array}{c}2.6 \\
3.2 \\
1\end{array}$ & $\begin{array}{l}55.1 \\
22.2 \\
22.7\end{array}$ & 8.65 & $358 \pm 62$ & $\begin{array}{l}655 \pm 88 \\
\text { Span and Tween } \\
\text { Were doubled }\end{array}$ \\
\hline 5 & $\begin{array}{c}\text { Span } 80 \\
\text { Tween } 80 \\
\text { Tergitol }\end{array}$ & $\begin{array}{l}2.6 \\
3.2 \\
3.7\end{array}$ & $\begin{array}{l}41.5 \\
16.7 \\
41.8\end{array}$ & 9.68 & $\sim \mathrm{I} .4 \mu \mathrm{m}$ & $\begin{array}{l}\quad \geq 2 \mu \mathrm{m} \\
\text { Span and Tween } \\
\text { Were doubled }\end{array}$ \\
\hline
\end{tabular}

Notes: The particle sizes of blank nanogels (Blank-NG) and CA encapsulated nanogels (CA-enc-NG) were measured by DLS. 
at $5000 \mathrm{rpm}$ for 10 minutes, and both the precipitate and floating mass were discarded. The clear supernatant was transferred into an Amicon stir cell, and the nanogels were washed with $800-1000 \mathrm{~mL}$ water. At the end, about $20 \mathrm{~mL}$ nanogel suspension was obtained and freeze-dried with a $5 \mathrm{~L}$ ModulyoD freeze dryer (Thermo Fisher Scientific).

\section{Preparation of CA Conjugated Nanogels}

In this approach, blank PAAm nanogels were synthesized in the absence of CA, washed with ethanol and water to eliminate the surfactants, and then freeze-dried. After the blank nanogels were suspended in solution, the amine groups on the nanogels were activated by Sulfo-SMCC, and then the maleimide-activated nanogels were linked to the amine groups on the CA in the solution. $50 \mathrm{mg}$ blank PAAm nanogels were prepared by a procedure described previously. ${ }^{17}$ They were first suspended in $2.5 \mathrm{~mL} 10 \mathrm{mM}$ MOPS pH 7.2, into which $3 \mathrm{mg}$ Sulfo-SMCC (Sulfosuccinimidyl-4-[N-maleimidomethyl] cyclohexane1-carboxylate) was added. The mixture was stirred at $600 \mathrm{rpm}$ for 2 hours at room temperature, transferred to an Amicon cell and washed with $60 \mathrm{~mL}$ MOPS buffer. A $10 \mathrm{~mL} 1 \mathrm{mg} / \mathrm{mL}$ CA solution was added into the resulting mixture and the mixture was stirred at $600 \mathrm{rpm}$ overnight at room temperature. $1.736 \mathrm{mg}$ L-cysteine was then added, and the mixture was stirred for 2 more hours. Finally, the nanogels were washed in an Amicon cells with $60 \mathrm{~mL}$ MOPS so as to eliminate unreacted enzymes and L-cysteine.

\section{Enzyme Activity Assay ("pNPA Assay")}

The activity of CA in the nanogels was quantified by the $p$ NPA assay. The hydrolysis of $p$-nitrophenyl acetate $(p \mathrm{NPA})$ is catalysed by CA as shown below. The reaction rate was measured by monitoring the absorbance of the reaction product, $p$-nitrophenol $(p \mathrm{NP})$, at $400 \mathrm{~nm}$, over time. A CA inhibitor, Acetazolamide, was then added to the sample, so as to inhibit the CA activity. The background reaction rate, without $\mathrm{CA}$ catalysation, was remeasured. The difference of the two reaction rates was calculated as the adjusted slope $\left(m_{a d j}\right) .{ }^{45}$

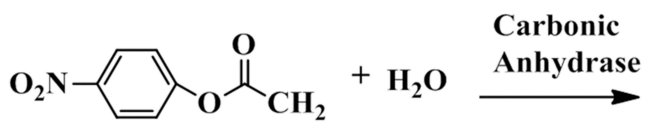

A $10 \mathrm{mM} p$ NPA solution was prepared by dissolving $p \mathrm{NPA}$ in an acetone/water $(40 \% \mathrm{v} / \mathrm{v})$ mixture, and a 10 $\mathrm{mM}$ Acetazolamide solution was prepared by dissolving Acetazolamide in a DMSO/water $(10 \% \mathrm{v} / \mathrm{v})$ mixture. In a $3 \mathrm{~mL}$ cuvette, $1.9 \mathrm{~mL}$ of a $10 \mathrm{mM}$ Bicine buffer $(\mathrm{pH}$ 8.0), $50 \mu \mathrm{L}$ of a $p$ NPA solution and $50 \mu \mathrm{L}$ of a $\mathrm{CA}$ solution or nanogel suspension were mixed quickly and thoroughly. The reaction rate was monitored by recording the sample absorbance, at a $400 \mathrm{~nm}$ wavelength, over time. After recording for 100 to 150 seconds, a background rate was monitored by adding $50 \mu \mathrm{L}$ Acetazolamide solution into the cuvette, to reach a final concentration of $0.25 \mathrm{mM}$, so as to inhibit the CA activity; then the sample absorbance was recorded over time for another 100 to 150 seconds. The adjusted slope was derived by subtracting the slope of the background rate from that of the reaction rate. The adjusted slope is the increase of the absorbance of $p$-nitrophenol over time (Equation 2):

$$
m_{a d j}=\partial A_{p N P} / \partial t
$$

The reaction velocity, or the velocity of the product formation, is calculated using Equation 3, combined with the Beer-Lambert law and Equation 2.

$$
\nu=\frac{\partial C_{p N P}}{\partial t}=\frac{\partial A_{p N P}}{\partial t \times \varepsilon_{p N P} \times L}=\frac{m_{a d j}}{\varepsilon_{p N P} \times L}=\frac{m_{a d j}}{\varepsilon_{p N P}}
$$

Here $\varepsilon_{p N P}$ and $C_{p N P}$ are the extinction coefficient and concentration of $p$-nitrophenol, respectively, and $L$ is the length of the light path in $\mathrm{cm}$, which is $1 \mathrm{~cm}$.

Combining with Equation 3, the catalytic efficiency of $\mathrm{CA}, k_{\text {cat }} / K_{m}$, is calculated using Equation 4:

$$
\frac{k_{c a t}}{K_{m}}=\frac{\nu}{C_{p N P A} \times C_{C A}}=\frac{m_{a d j}}{\varepsilon_{p N P} \times C_{p N P A} \times C_{C A}}
$$

Here $C_{p N P A}$ is the concentration of the substrate, $p$-nitrophenyl acetate, and $C_{C A}$ is the concentration of CA. This reaction occurred at a sub-saturating $p$ NPA concentration; therefore, we assumed a constant $k_{c a t} / K_{m}$ in this study.

As shown in Equation 4, the adjusted slope $\left(m_{a d j}\right)$ is proportional to the concentration of active $\mathrm{CA}\left(C_{C A}\right)$. A calibration curve was constructed by plotting $m_{a d j}$ against $C_{C A}$ (Figure S-1 in the Supporting Information), and this curve was used for calculating the amount of

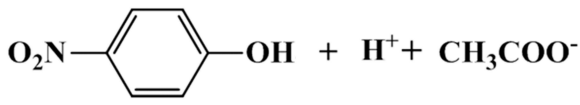


active $\mathrm{CA}$ in the nanogels, assuming a constant specific activity. All experiments were repeated in triplicates.

\section{The CA Activity Affectation by: AOT, Brij 30, The Initiator and 95\% Ethanol}

The following solutions were prepared: $0.08 \mathrm{M}$ AOT, 0.19 $\mathrm{M}$ Brij 30, and the initiator solution (mixture of $0.1 \% \mathrm{w} / \mathrm{W}$ Ammonium persulfate and 1\% v/v TEMED). The concentrations of AOT, Brij 30 and initiator were the same as the concentrations used in standard nanogels preparation. ${ }^{17}$ The $95 \%$ ethanol case was also tested since $95 \%$ ethanol was used to wash the nanogels. An aliquot of CA solution was mixed with the surfactants and initiator solution. For control, an aliquot of CA solution was mixed with $10 \mathrm{mM}$ MOPS of $\mathrm{pH}$ 7.2. The enzyme activity in each mixture was measured immediately after it was prepared, as well as after 2 hours of incubation at room temperature.

\section{Coomassie Blue Protein Assay}

The total amount of CA (active and denatured) was measured, using the Coomassie Plus Assay Kit as described in the instructions provided by ThermoFIsher. ${ }^{46}$ Notably, both active and denatured CA do bind with Coomassie Blue, showing increased absorbance at $595 \mathrm{~nm}$. Briefly, the sample was prepared by mixing $1.5 \mathrm{~mL}$ of the Coomassie Plus Reagent and a $50 \mu \mathrm{L}$ CA solution, or the CA-nanogel suspension. The sample was then incubated at room temperature for $10 \mathrm{~min}$ utes, so as to obtain the most consistent results. Light absorbance at a wavelength of $595 \mathrm{~nm}$ was recorded. A calibration curve was constructed by plotting the absorbance against the CA concentration, including a sample without $\mathrm{CA}$, and the total CA in the nanogels was quantified, based on this calibration curve. All experiments were repeated in triplicates.

Our experimental data show that AOT and Brij 30 do as well increase the absorbance of Coomassie Blue at 595 $\mathrm{nm}$. Therefore, a suspension of blank nanogels was prepared using the same conditions as for the CA encapsulated nanogels, to be used as a background (Figure S-2 in the Supporting Information), so as to improve the accuracy of the nanogels' protein quantification.

\section{Dapoxyl Sulfonamide Binding Assay}

The binding of sulfonamide fluorophores to holo-CA, in which $\mathrm{Zn}^{2+}$ is present at its active site, was studied. In brief, Dapoxyl sulfonamide (DPS) was added into the solution, and the binding of DPS to CA is observed through the increased fluorescence of the DPS. A 2-5 $\mu \mathrm{M}$ CA solution or 2-5 mg/
mL CA-nanogel suspension was prepared in $10 \mathrm{mM}$ MOPS of $\mathrm{pH}$ 7.2. A fourfold molar excess of DPS was then added into the solution, or into the suspension. Spectra were collected on a Horiba FluoroMax-3 fluorometer by exciting the sample at $365 \mathrm{~nm}$ and recording the resulting emission from $430 \mathrm{~nm}$ to $700 \mathrm{~nm}$, in $1 \mathrm{~nm}$ increments, with an integration time of $0.5 \mathrm{sec}$.

A non-fluorescent sulfonamide inhibitor, Acetazolamide, which has a much tighter binding affinity $\left(K_{d}=0.02 \mu \mathrm{M}\right){ }^{47}$ was then added into the solution to reach a final concentration of $0.25 \mathrm{mM}$, so as to replace DPS. After the solution was equilibrated for $15 \mathrm{~min}$, the background fluorescence was measured. All experiments were repeated in triplicate.

The excitation, emission, quantum yield and CA binding affinity of DPS are listed in Table 3. DPS was synthesized from a commercially available precursor, Dapoxyl Sulfonyl Chloride (see the Supporting Information).

\section{$\mathrm{Zn}^{2+}$ Sensing by Apo CA and Apo CA Encapsulated or Conjugated Nanogels} $\mathrm{Zn}^{2+}$ was first removed from the CA and CA nanogels; the procedure is detailed in the Supporting Information. In summary, the holo-CA and the holo-CA nanogels were incubated with 2,6 pyridine dicarboxylic acid (DPA) at $4^{\circ} \mathrm{C}$ for 48 hours, then washed with $10 \mathrm{mM}$ MOPS, of $\mathrm{pH} 7.2$, in pre-treated, low metal, Amicon stirred cells, so as to remove the Zn-DPA complex and excess DPA, resulting in apo $\mathrm{CA}$ and apo $\mathrm{CA}$ nanogels.

A 2-5 $\mu \mathrm{M}$ apo CA solution or 2-5 $\mathrm{mg} / \mathrm{mL}$ nanogel suspension was prepared in $10 \mathrm{mM}$ MOPS of $\mathrm{pH} 7.2$, containing 10 $\mathrm{mM}$ nitrilotriacetic acid (NTA). A fourfold molar excess of DPS was then added into the solution or suspension. Spectra were collected on a Horiba FluoroMax-3 fluorometer by exciting the sample at $365 \mathrm{~nm}$ and recording the resulting emission from $430 \mathrm{~nm}$ to $700 \mathrm{~nm}$, in $1 \mathrm{~nm}$ increments, with an integration time of $0.5 \mathrm{sec}$. After each successive spectrum was collected, an aliquot of zinc chloride was added, and the solution was equilibrated for 15 min before the next spectrum was collected. The samples were prepared and continuously stirred by a magnetic stir bar in a quartz cuvette which was kept at

Table 3 Dapoxyl Sulfonamide as a Fluorescent Binding Ligand of CA

\begin{tabular}{|l|c|c|c|c|c|}
\hline & & $\begin{array}{c}\lambda_{\text {EX }} \\
(\mathbf{n m})\end{array}$ & $\begin{array}{c}\lambda_{\text {EM }} \\
(\mathbf{n m})\end{array}$ & $\begin{array}{c}\text { Quantum } \\
\text { Yield }\end{array}$ & $\begin{array}{c}\mathbf{K}_{\mathbf{d}} \\
(\boldsymbol{\mu M})\end{array}$ \\
\hline Dapoxyl & Free & 365 & 615 & 0.01 & N/A \\
sulfonamide & Bound & 365 & 535 & 1.00 & 0.13 \\
\hline
\end{tabular}

Notes: $\lambda_{E X}$ and $\lambda_{E M}$ are the excitation and the emission wavelengths of DPS, and $K_{d}$ is the binding affinity of DPS to CA. Data from Thompson et al. ${ }^{59}$ 
$25^{\circ} \mathrm{C}$ by a water-jacketed temperature-controlled cuvette holder. All experiments were repeated in triplicate.

NTA was used as a chelating agent to bind with the majority of $\mathrm{Zn}^{2+}$ and therefore maintaining a low free $\mathrm{Zn}^{2+}$ concentration in solution. The actual free $\mathrm{Zn}^{2+}$ concentrations in the calibration solutions, at a given $\mathrm{pH}$, temperature, and ionic strength, were computed using a web-based computer program, Webmaxclite v1.15. ${ }^{48}$

Once the free $\mathrm{Zn}^{2+}$ concentrations were calculated, the apparent $K_{d}$ for $\mathrm{Zn}^{2+}$ and for the CA encapsulated or conjugated nanogels was derived, based on Equation 5:

$$
K_{d}=\left[Z n^{2+}\right]_{\text {free }} \times \frac{F_{\text {max }}-F}{F-F_{\text {min }}}
$$

Here $F_{\max }$ and $F_{\min }$ refer to the fluorescence of the $\mathrm{Zn}^{2+}$ saturated state (max) and the $\mathrm{Zn}^{2+}$ depleted state (min), respectively.

\section{Results}

\section{Nanomatrix Preservation of Enzyme Activity}

\section{PAAm Matrix Stabilized by AOT and Brij 30}

The CA encapsulated nanogels (sample A in Figure 2) were fabricated by the standard PAAm nanogel preparation procedure, ${ }^{17}$ as detailed in the Methods section.

The active CA presence in the nanomatrix was quantified, by the enzyme activity assay, comparing with blank
PAAm nanogels. The active CA amount in the nanomatrix was estimated to be $3.1 \mathrm{mg} \mathrm{CA}$ per $1 \mathrm{~g}$ of nanogels. The total CA protein content in the nanomatrix (sample A) was estimated to be $17.2 \mathrm{mg}$ CA per $1 \mathrm{~g}$ of nanogels by the Coomassie Blue protein assay, as detailed in the Methods section. The typical yield of the nanogels was about 1 g. By using both the enzyme activity assay and the Coomassie Blue assay, it was estimated that, out of the $43 \mathrm{mg}$ CA added into the reaction, $17.2 \mathrm{mg} \mathrm{CA}$ was encapsulated, and $3.1 \mathrm{mg}$ CA retained its activity inside the nanogels.

Experiments were then performed to uncover the factors that caused the $\mathrm{CA}$ deactivation. As shown in Figure 3, the CA activity decreases dramatically upon mixing with the anionic surfactant AOT; and only 20\% of the CA activity remains after incubation with $95 \%$ ethanol for 2 hours at room temperature. In contrast, $70 \%$ and $80 \%$ of the CA activity remains after incubating with Brij 30 and initiator solution, respectively, indicating that $\mathrm{CA}$ is stable in the presence of the nonionic surfactant Brij 30 and unaffected by the free radicals generated by the initiator. Additionally, it has been reported that the enzyme activity of both lipase and horseradish peroxidase was enhanced in micelles stabilized by nonionic surfactants such as Brij 30 and Tween 80. ${ }^{49,50}$ Therefore, the use of nonionic surfactants in nanogel preparation is expected to better preserve the CA activity.

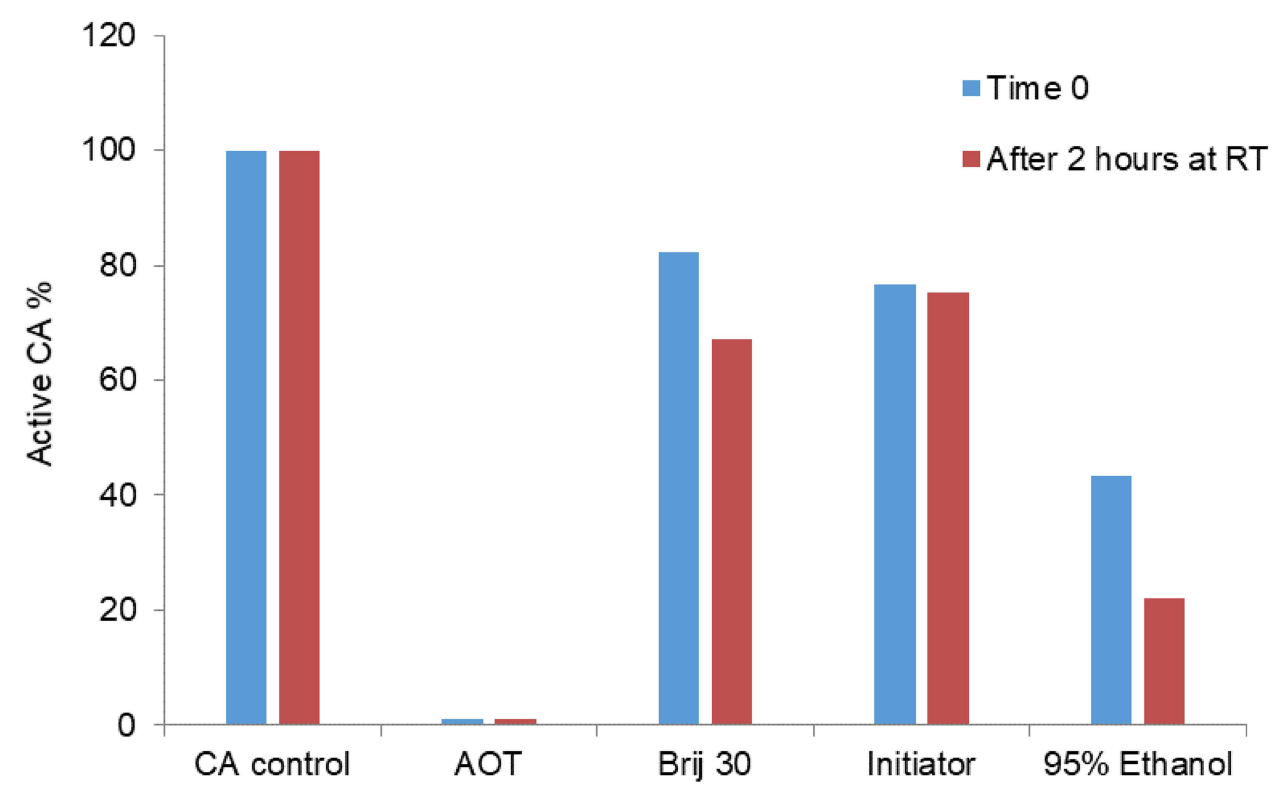

Figure 3 The CA activity affectation by AOT, Brij 30, initiator and $95 \%$ ethanol.

Notes: The anionic surfactant AOT has significant impact on the CA activity, so does $95 \%$ ethanol. In contrast, CA is relatively stable in the presence of the nonionic surfactant Brij 30 and only little affected by the free radicals generated by the initiator. 


\section{PAAm Matrix Stabilized by Non-lonic Surfactants}

We have successfully used the Hydrophile-Lipophile Balance (HLB) concept as a guide to identify suitable multi-surfactant systems, as explained in the Methods section. The HLB values of the nonionic surfactants used in this work are shown in Table 1. As shown in Table 2, five multi-surfactant systems were used to produce particles, with sizes ranging from $40 \mathrm{~nm}$ to $2 \mu \mathrm{m}$. Note that the size of the CA encapsulated nanogels is always larger than that of the blank nanogels synthesized in the same surfactant system. In some cases (system 4 and 5 in Table 2), higher amounts of surfactant were needed for preparing the CA encapsulated nanogels, the amounts of Span 80 and Tween 80 were doubled. This is possibly because the presence of CA in the water droplets increases the density of the aqueous phase, therefore requiring more surfactant to provide enough surface tension to stabilize the micelles.

Due to the favourable size and high yield, particles produced by system \#2 (Span 80, Tween 80 and Brij 30, in Table 2) were chosen for further experiments. An illustration of the water droplets stabilized by this multi-nonionic surfactant system is shown in Figure 4A. We hypothesized that Span 80, Tween 80 and Brij 30 formed a layer of surfactants surrounding the nanometer-sized water droplets, which provide enough surface tension to stabilize the water droplets in the water-in-oil microemulsion. Notably, the more hydrophilic surfactant Tween 80 (high HLB) is close to the aqueous phase, while the more lipophilic surfactant Span 80 (low HLB) is close to the oil phase.

The SEM image of the nanogels reveals that the average size of the dehydrated nanogels is $25-30 \mathrm{~nm}$ (Figure 4B), when the nanogels are dried on a metal grid for imaging (see the Supporting Information). In comparison, the diameter of the swelling nanogels in aqueous solution was determined to be $73 \pm 13 \mathrm{~nm}$ by Dynamic Light Scattering (Table 2).

CA Conjugated Nanogels. Compared to the encapsulation method, we note that the fabrication and separation procedure of the CA conjugated nanogels is more straightforward: The nanogels were first fabricated and washed with excess ethanol to remove surfactants and unreacted monomer. The enzyme was then covalently linked onto the surface of the nanogels, as described in the Methods section. A control reaction was also performed by mixing only nanogels and CA without adding Sulfo-SMCC, and the result showed no CA activity, ${ }^{58}$ confirming a covalent linkage was formed between the nanogels and CA.

Enzyme Activity of CA in Nanogels. Figure 2 shows the amount of CA activity in the CA encapsulated and conjugated nanogels. The combination of the biofriendly surfactant system (Span 80/Tween 80/Brij 30) and the biofriendly separation process $\left(\mathrm{Al}_{2} \mathrm{O}_{3}\right.$ absorptive filtration) seems to have increased the CA activity in the CA encapsulated nanogels by a factor of 3- to 4-fold (Sample D), compared to the standard nanogel preparation procedure (AOT/Brij 30 surfactant system and ethanol washing, Sample A). Per 1 g nanogels, sample D contains $11.3 \mathrm{mg}$ active CA, while sample A contains $3.1 \mathrm{mg}$ active CA. We assumed that $\sim 17.2 \mathrm{mg}$ CA was encapsulated in the nanogels (same as sample A in the previous discussion), and that $\sim 66 \%$ of the CA encapsulated in sample D retained its activity. Adding a higher amount of $\mathrm{CA}$ at the start of the nanogel preparation did not result in a higher active CA loading; sample E contains $10.5 \mathrm{mg}$ active CA per $\mathrm{g}$ nanogels. Therefore,
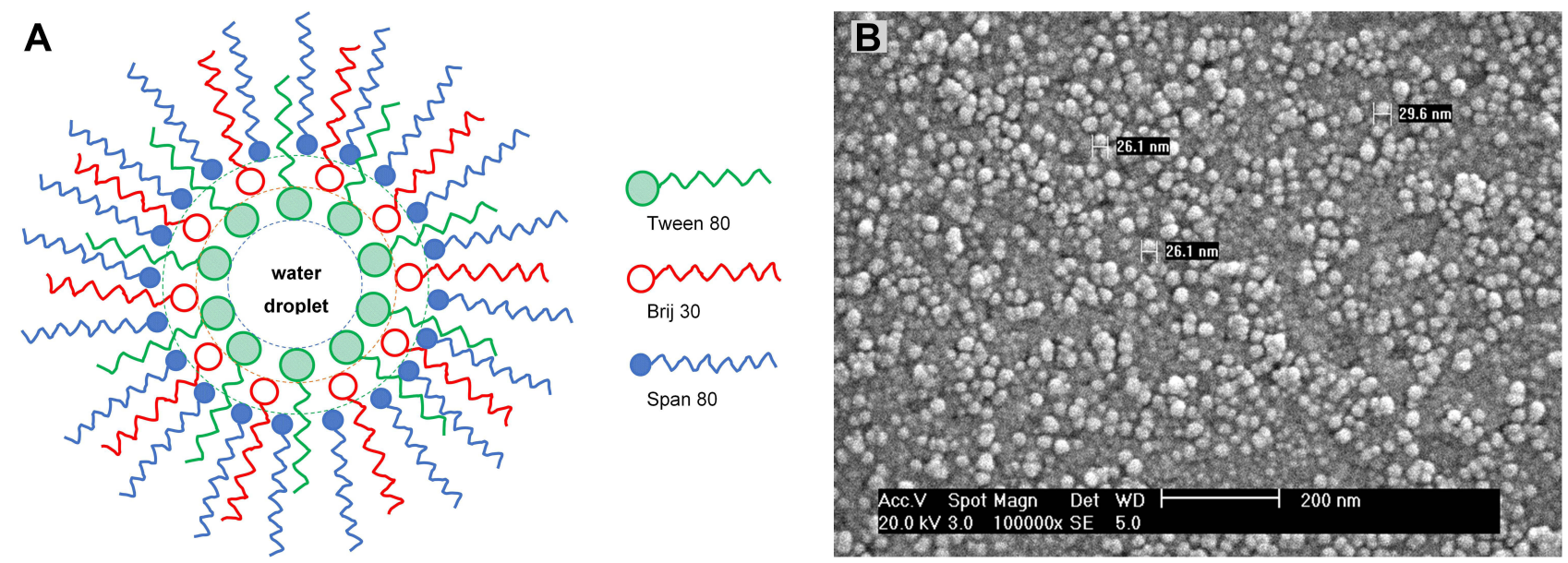

Figure 4 (A) Schematic illustration of a water droplet stabilized by the multi-nonionic surfactant system in the water-in-oil microemulsion. (B) SEM image of CA encapsulated nanogels prepared in a Span 80, Tween 80 and Brij 30 stabilized microemulsion. 
a $43 \mathrm{mg}$ CA initial input was sufficient. The typical yield of the nanogels was about $1 \mathrm{~g}$. Notably, the encapsulation efficiency was calculated as the percentage of encapsulated active CA in the initial input $43 \mathrm{mg} \mathrm{CA}$. The encapsulated efficiency of sample D was thus calculated to be $26.3 \%$, and that of sample A to be $7.2 \%$.

In $\mathrm{CA}$ conjugated nanogels (sample $\mathrm{F}$ ), the $\mathrm{CA}$ activity was increased 2-folds, compared to the CA encapsulated nanogels prepared by using Span 80/Tween 80/Brij 30 and $\mathrm{Al}_{2} \mathrm{O}_{3}$ absorptive filtration (sample $\mathrm{D}$ and $\mathrm{E}$ in Figure 2). Furthermore, it was almost sevenfold higher than that in the CA encapsulated nanogels prepared by the standard method (sample A). Active CA was estimated to be $22.5 \mathrm{mg}$ per $1 \mathrm{~g}$ nanogels.

Ligand Binding Ability of CA in Nanogels. The binding of sulfonamide fluorophores to holo-CA, in which $\mathrm{Zn}^{2+}$ is present at its active site, was studied, as detailed in the Methods section. Figure 5A shows the fluorescence change of DPS upon addition of either CA encapsulated nanogels or blank nanogels. In the case of CA encapsulated nanogels, the fluorescence difference, between before and after the addition of Acetazolamide, is contributed by the encapsulated active CA. We notice that the fluorescent background after the addition of Acetazolamide is much higher than the background of free DPS in solution. Moreover, blank nanogels also enhance the fluorescence of DPS. We speculated that the residual surfactants in the nanogels may also interact with DPS and thus increase its fluorescence.

The likelihood of interference by the surfactants with the sulfonamide fluorophores, DPS and Dansylamide, was tested by monitoring the spectra of the

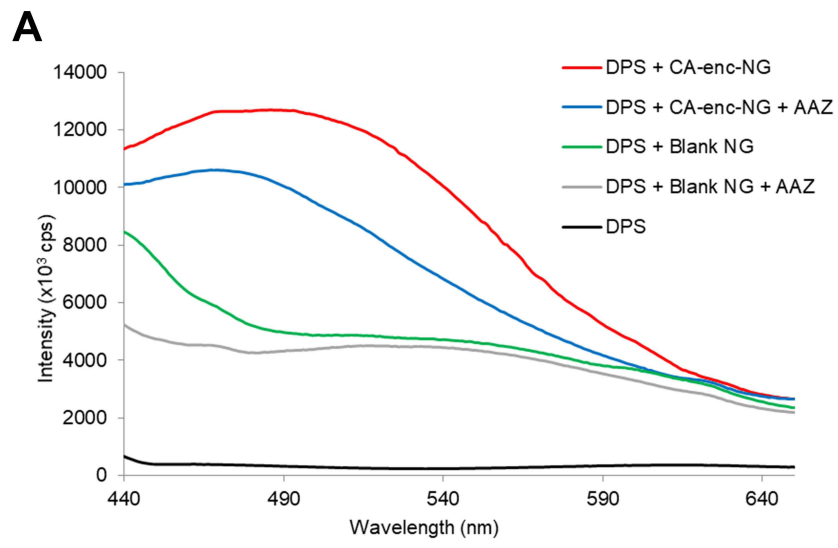

fluorophores, in the presence and absence of the surfactants (Figure S-3 in the Supporting Information). Figure S-3 shows that all the non-ionic surfactants used in the nanogel preparation (Brij 30, Tween 80, Span 80) did enhance the fluorescence of both DPS and Dansylamide. Although AOT, as an anionic surfactant, does not enhance the fluorescence of DPS, AOT does deactivate CA (Figure 3).

The above fluorescence enhancement, caused by the residual surfactants, does form a fluorescence background. However, this background is not affected by the Acetazolamide. The fluorescence of DPS, in the presence of blank nanogels, remains at the same level after adding Acetazolamide (Figure 5A). Notably, both blank and CA encapsulated nanogels were synthesized using the same surfactant system; and both were purified using $\mathrm{Al}_{2} \mathrm{O}_{3}$ absorptive filtration.

In the case of $\mathrm{CA}$ conjugated nanogels, Figure 5B shows the fluorescence change of DPS following the binding of DPS to CA conjugated nanogels. The fluorescence difference, between before and after the addition of Acetazolamide, is contributed by the conjugated active CA. We notice that after adding Acetazolamide, the fluorescence decreased to almost the same level as the fluorescence of free DPS in solution. This is because almost all the CA-bound DPS was replaced by Acetazolamide which is a non-fluorescent molecule. These results establish that the binding of DPS to active CA contributes the most to the fluorescence increase of DPS, while the interference from residual surfactants with DPS is minimal.

B

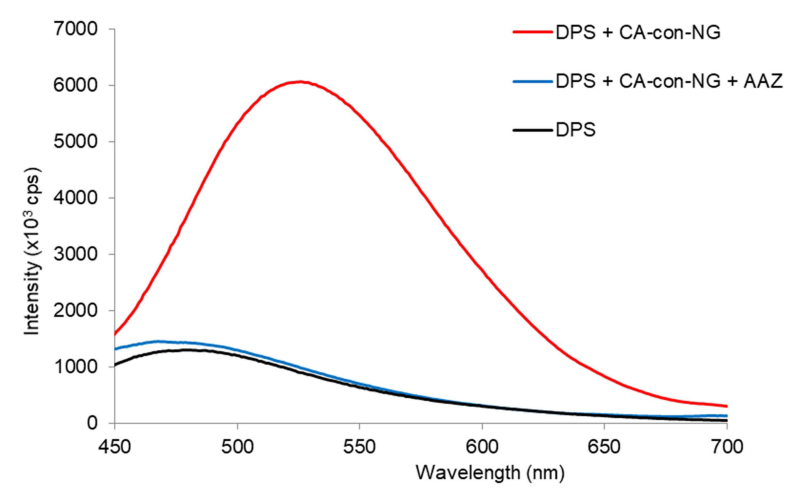

Figure 5 (A) The fluorescence of DPS in the presence of either CA encapsulated nanogels or blank nanogels. CA encapsulated nanogels: CA-enc-NG, red and blue. Blank nanogels: Blank-NG, green and grey. After recording the spectra of DPS in the presence of the nanogels, Acetazolamide (AAZ) was added, and the background fluorescence was recorded (blue and gray). (B) The fluorescence of DPS in the presence of CA conjugated nanogels. CA conjugated nanogels: CA-con-NG, red. The background fluorescence is measured after addition of Acetazolamide (blue), compared to DPS alone (black). The nanogels are washed with ethanol and water before CA is conjugated onto them. Therefore, the interference of the residual surfactants is minimal, and the enzyme structural integrity appears to be well preserved. 


\section{$\mathrm{Zn}^{2+}$ Sensing by CA-Nanogels}

Note that practically all the $\mathrm{Zn}^{2+}$ was removed from the holo-CA by incubating the holo-CA with DPA, a zinc chelator, before performing the $\mathrm{Zn}^{2+}$ sensing experiments (see the Supporting Information). The zinc sensing mechanism is shown in Figure 1. Briefly, apo-CA first binds with free $\mathrm{Zn}^{2+}$ and produces holo-CA. The sulfonamide fluorophore, DPS, then binds to the holo-CA, which induces an increase in its fluorescence. The commercial bovine CA zinc binding dissociation constant, $K_{\mathrm{d}}$, was determined to be $29 \pm 7 \mathrm{pM}$ (Figure 6). As a reference, the reported $K_{\mathrm{d}}$ of the wild-type human CA II is $\sim 1 \mathrm{pM}$, at $p \mathrm{H} 7 .{ }^{30}$

Recapitulating, practically all the $\mathrm{Zn}^{2+}$ was first removed from the holo-CA-encapsulated nanogels, as detailed in the Methods section. Also, the zinc binding affinity of the apoCA-encapsulated nanogels was tested by measuring the fluorescence of the nanogels in the presence of DPS, varying the concentrations of the free zinc. Notably, these tests showed no fluorescence change at varying free $\mathrm{Zn}^{2+}$ levels (Figure S-4 in the Supporting Information).

In contrast to the CA-encapsulated nanogels, zinc sensing was successful when using apo-CA-conjugated nanogels (Figure 6). The zinc binding affinity of the conjugated CA on the nanogels' surface was measured from the zincdependent increase in the fluorescence, which is detailed in the Methods section. The zinc dissociation constant $K_{\mathrm{d}}$ was determined to be $9.4 \pm 1.2 \mathrm{pM}$. Importantly, we see that these CA conjugated nanogels are highly sensitive to minute concentrations of $\mathrm{Zn}^{2+}$, down to $0.1 \mathrm{pM}$, with an excellent dynamic range up to $100 \mathrm{pM}$.

\section{Discussion and Conclusions}

Many attempts have been made to immobilize CA in various supports, including hydrogels, for the biocatalysis of the reversible conversion of $\mathrm{CO}_{2}$ to bicarbonate. ${ }^{35-41}$ Studies by Fierke and Thompson have demonstrated another unique application of CA, namely as a zinc biosensor, with advantages well-discussed in the literature. ${ }^{25-31}$ Here we report, for the first time, a proof-of-concept study of combining active $\mathrm{CA}$ with nanogels. By immobilizing $\mathrm{CA}$ in nanogels, we hoped to provide additional advantages, compared to previous methods of immobilization. Advantages such as optimal matrix protection and targeted delivery, and thus use these nanogels as zinc nano-biosensors, both in-vitro and invivo. Two universal methods for $\mathrm{CA}$ immobilization were established in this study, encapsulation and surface conjugation. For both immobilization methods, the catalytic activity and ligand binding of the CA nanogels was quantified, and the nanogels were tested as highly sensitive zinc sensors.

The water-in-oil micro-emulsification is a commonly used technique to synthesize nanogels. Two steps are indispensable to the success of the procedure: the use of surfactants to stabilize the ensuing microemulsion, and the purification step at the end of the synthesis so as to remove

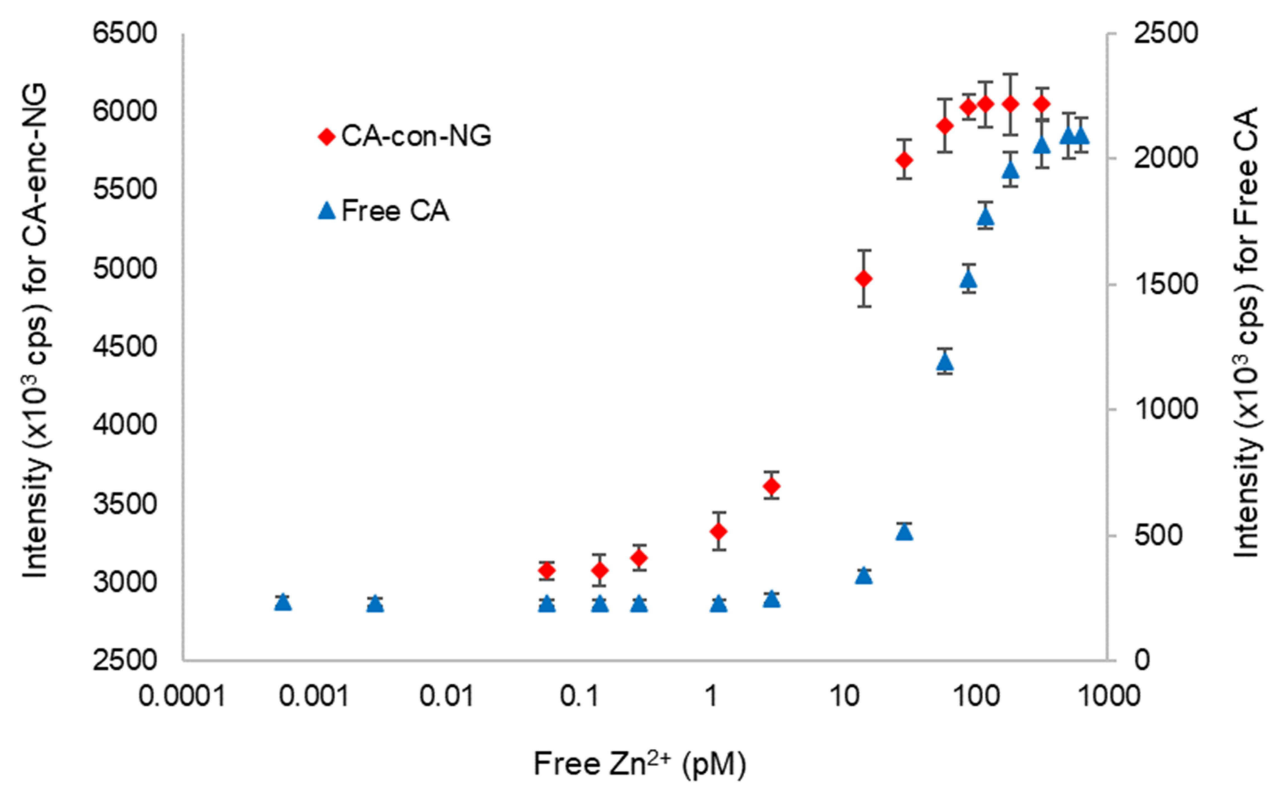

Figure 6 Free $\mathrm{Zn}^{2+}$ sensing using the CA conjugated nanogels (CA-con-NG) and free CA. The Zn dissociation constant, $K_{d}$, of CA-con-NG was calculated as $9.4 \pm 1.2$ pM (red), from a fit of Eq.5 (see the Methods section). The $K_{d}$ of free CA in solution was calculated as $29 \pm 7 \mathrm{pM}$ (blue). The experiment was performed in $10 \mathrm{mM}$ MOPS (pH 7.2 ) containing $10 \mathrm{mM} \mathrm{NTA} \mathrm{(nitrilotriacetic} \mathrm{acid)} \mathrm{and} \mathrm{various} \mathrm{concentrations} \mathrm{of} \mathrm{zinc,} \mathrm{at} 25^{\circ} \mathrm{C}$. 
the surfactants. The standard nanogel synthesis procedure uses AOT, an anionic surfactant, and a purification step by ethanol washing, which we showed to greatly damage the enzyme activity. In the present study, we implemented major improvements in the above two standard synthesis steps, so as to best preserve the biological integrity of CA: The use of (1) nonionic surfactants and of (2) $\mathrm{Al}_{2} \mathrm{O}_{3}$ adsorptive filtration. With the help of the HydrophileLipophile Balance (HLB) concept, we have identified and designed a suitable multi-surfactant system that consists of three surfactants, having low, medium and high HLB. We hypothesized that the above biofriendly surfactants formed a structured layer of surfactants surrounding the "nano-reactors". Inside these "nano-reactors", the CA was immobilized in the nanogels via in situ polymerization. In the $\mathrm{Al}_{2} \mathrm{O}_{3}$ adsorptive filtration step, $\mathrm{Al}_{2} \mathrm{O}_{3}$ was added to the microemulsion at the end of polymerization reaction. The nanogels in the aqueous phase were adsorbed onto the $\mathrm{Al}_{2} \mathrm{O}_{3}$ surface, leaving most of the surfactants in the discarded hexane phase. By keeping the nanogels in the aqueous phase throughout the purification process, the biological integrity of the CA was preserved. The use of HLB to design a multi-surfactant system and the use of the $\mathrm{Al}_{2} \mathrm{O}_{3}$ adsorptive filtration also highlight the novelty of this study.

As demonstrated by the $p$ NPA assay, up to $11.3 \mathrm{mg}$ active CA was encapsulated per $1 \mathrm{~g}$ of nanogels prepared by the improved process. This is almost four-fold increase compared to nanogels prepared by the standard process (3.1 $\mathrm{mg}$ active CA). As discussed in the Results section, we estimated that $\sim 17.2 \mathrm{mg}$ total CA was encapsulated in the nanogels. Therefore, about $66 \%$ of the encapsulated $\mathrm{CA}$ retained its activity. There are two extreme ways to interpret the activity of the CA encapsulated in the nanogels: 1) $66 \%$ of a given CA molecule was $100 \%$ active while the rest of the CA molecules was completely deactivated; 2) all the enzyme molecules have, on average, $66 \%$ of their original catalytic activity. The latter may be closer to the actual situation. We speculate that the specific activity of CA in the nanogels could be lowered because of the following reasons: 1) The diffusion rate of the substrate, $p$-nitrophenyl acetate, is possibly slower inside the nanogels than in solution. 2) The active site in some CA molecules is possibly blocked by the nanomatrix; therefore, it is more difficult for the substrate to reach the active site in the enzymes. 3) Due to the catalysis of the enzyme and the slower diffusion rates of the products, the local concentrations of the reaction products ( $p$-nitrophenol, $\mathrm{H}^{+}$ and $\mathrm{CH}_{3} \mathrm{COO}^{-}$) inside the nanogels may be higher than their concentrations in solution. This would lead to a lower local $\mathrm{pH}$ inside the nanogels, at which the absorbance of $p$-nitrophenol is also lower. The activity of CA could be decreased too if the local $\mathrm{pH}$ is lower (the reaction was carried out in $10 \mathrm{mM}$ Bicine buffer $\mathrm{pH}$ 8.0). All these factors may result in a decrease in the CA specific activity and an under-estimation of the active CA loading percentage.

The sulfonamide binding has also demonstrated that a significant fraction of the enzymes retained their structural integrity. Upon mixing with the CA encapsulated nanogels, the fluorescence of DPS significantly increased. After the addition of Acetazolamide, the fluorescence of DPS decreased. Note that the fluorescence difference, between before and after the addition of Acetazolamide, is contributed by the active CA. We also notice that the CA encapsulated nanogels have a high fluorescence background, after the addition of Acetazolamide. Moreover, blank nanogels prepared by the same process, the improved process, show a high background as well. One of the contributing factors to this high background is the residual nonionic surfactants in the nanogels. The residual surfactants interact with DPS and thus increase its fluorescence, and this enhancement is not affected by Acetazolamide. We also believe that the PAAm nanomatrix affected the binding behaviour of the sulfonamides. It is likely that the diffusion is slower for the hydrophobic sulfonamide molecules inside the hydrophilic 3Dstructured PAAm matrix, compared to the diffusion of these molecules in solution. This may change the thermodynamics and kinetics of their binding behaviour.

Zinc sensing was limited using the CA-encapsulated nanogels. One possible reason is that the fluorescence of DPS is greatly enhanced by residual surfactants; therefore, it is difficult to detect the small fluorescence change caused by the addition of free $\mathrm{Zn}^{2+}$. Another possible reason for the above results is that $\mathrm{Zn}^{2+}$ is difficult to remove from the CA encapsulated inside nanogels, due to the high zinc affinity (pM) and the slow zinc dissociation rate constant of the wild type CA. ${ }^{29}$ It has been reported that $\mathrm{Zn}^{2+}$ is difficult to remove from some CA fluorescence conjugates. In this case, zinc was substituted with cobalt (II) before conjugation, then the fluorophore was attached to the cobalt bound enzyme and then cobalt was removed. This is because CA binds cobalt much less tightly than zinc. ${ }^{28}$ For that reason, $\mathrm{Co}^{2+}$-bound $\mathrm{CA}$ was prepared and encapsulated in nanogels. However, under 
the conditions of the encapsulation procedure, CA activity was not retained, ${ }^{58}$ likely because $\mathrm{Co}^{2+}-\mathrm{CA}$ is less stable than the zinc-bound wild-type enzyme. The difficulty of removing $\mathrm{Zn}$ from encapsulated CA might be overcome by encapsulating the human CA II mutants, which possess a faster zinc dissociation rate constant. ${ }^{28}$

Nevertheless, the encapsulation method has a major advantage: the biological payload is protected by the PAAm nanomatrix from environmental damage (ie, protease attack, interfacial stress), thus potentially increasing the stability of the payload in vivo. ${ }^{51}$ More questions on the CA-encapsulated nanogels need to be answered. For example, we assumed a constant CA catalytic efficiency $k_{\text {cat }} / K_{m}$ so as to easily calculate the enzyme encapsulation efficiency. However, it is reported that the MichaelisMenten constant $\left(K_{m}\right)$ and the maximum velocity $\left(V_{\max }\right)$ of CA changed upon immobilization. ${ }^{52}$ Future work can be done to investigate the change in the kinetics of the enzyme's catalytic behaviour. Moreover, the matrix protection effects on CA, against protease attack, and harsher thermo or $\mathrm{pH}$ conditions, can be evaluated. Other proteins or enzymes, such as fluorescent proteins, ${ }^{18,53}$ with a simpler sensing mechanism, could be encapsulated in these nanogels as well for biosensing. These nanogels could be used as a delivery vehicle for biologics, and could offer many other advantages, such as co-delivery of multiple moieties, controlled release or stimuliresponsive release of the payload, and targeted delivery, both in vitro and in-vivo. ${ }^{11-13,22,54}$

In the conjugation approach, CA was covalently linked onto the surface of the nanogels, after the nanogel fabrication and purification process. Therefore, harsh conditions (ie, high/low $\mathrm{pH}$, ethanol washing) can be used to reduce their impurity levels (ie, surfactants) to a minimum, without affecting the biological payload. Comparing to the encapsulation method, the amount of active CA per $1 \mathrm{~g}$ nanogels was almost doubled. The active $\mathrm{CA}$ in the $\mathrm{CA}$ conjugated nanogels was estimated to be $22.5 \mathrm{mg}$ per $1 \mathrm{~g}$ nanogels. Note that the actual amount of CA conjugated onto the nanogels is limited by two factors: 1) the surface area of the nanogels, as CA is covalently linked to the amine groups on the surface of the nanogels; 2) the amount of amine-functional groups on the nanogel surface, which is determined by the amount of aminefunctionalized acrylamide monomer, N-(3-aminopropyl) methacrylamide hydrochloride (APMA). Although the amine groups are present both inside and on the surface of the nanogels, it is unlikely that CA could enter the particle matrix through the pores due to the relatively large size of the enzyme (5 $\mathrm{nm}$ in diameter). It was reported that the pore size of PAAm with a cross-linker /monomer molar ratio $(\% \mathrm{C})$ of $1.2 \%$ was estimated to be $\sim 7 \mathrm{~nm}$; the higher $\% \mathrm{C}$ the smaller the pore size. ${ }^{55}$ The PAAm nanogels used in this study have a cross-linker /monomer molar ratio of $\sim 11 \%$, we thus believe that the pore size is less than $7 \mathrm{~nm}$. Furthermore, we performed a control reaction by mixing only nanogels and $\mathrm{CA}$ in the absence of Sulfo-SMCC, and the resulting nanogels showed no CA activity. ${ }^{58}$ This proves that CA could not enter the nanogel matrix via diffusion and adsorption; therefore, crosslinking of CA via Sulfo-SMCC can only occur on the surface of the nanogels.

The sulfonamide binding has demonstrated that the fluorescence increase of DPS upon mixing with the CA conjugated nanogels was mostly contributed by the active CA. After the addition of Acetazolamide, the fluorescence background is almost at the same level as free DPS in solution. This proved that the residual surfactant level in CA conjugated nanogels is minimal. As discussed above, the enzymes were covalently linked onto the surface of the blank nanogels, after these nanogels were fabricated and washed with excess ethanol to remove surfactants. Moreover, the sulfonamides can easily reach the enzymes on the surface of the nanogels, without travelling into the matrix. Therefore, no potential diffusion difficulty is expected for the sulfonamides.

While this approach retains some of the advantages provided by the PAAm nanomatrix, such as inter- and intra-cellular targeting, ${ }^{22}$ the protection of the PAAm nanomatrix is not necessarily retained for the biologics. Nevertheless, zinc sensing by these CA conjugated nanogels was very successful, indicating that this method is quite promising for targeted intracellular zinc measurement. Meanwhile, the use of CA mutants could further enhance this method. Future work could evaluate the zinc selectivity of the CA conjugated nanogels in the presence of other covalent metal ions, the stability and reusability of these nanosensors, and test the feasibility of intracellular zinc sensing.

It is known that CA binds to $\mathrm{Zn}^{2+}$ with excellent selectivity, with a $K_{\mathrm{d}}$ at $\mathrm{pM}$ level. Other divalent metal cations bind to $\mathrm{CA}$ with much lower affinity. For example, the binding affinity of $\mathrm{CA}$ to $\mathrm{Mn}^{2+}, \mathrm{Co}^{2+}, \mathrm{Ni}^{2+}, \mathrm{Cd}^{2+}$ and $\mathrm{Fe}^{2+}$ is at $\mu \mathrm{M}$ to $\mathrm{nM}$ level, and the affinity to $\mathrm{Ca}^{2+}$ and $\mathrm{Mg}^{2+}$ is at $\mathrm{mM}$ level. Thus, any interference from these ions will only occur under extremely high interferent 
concentrations, which is not likely for biological samples. $\mathrm{Cu}^{2+}$ could potentially compete with $\mathrm{Zn}^{2+}$ for binding to $\mathrm{CA}$, since $\mathrm{Cu}^{2+}$ binds to $\mathrm{CA}$ with 10-fold higher affinity than $\mathrm{Zn}^{2+}$. However, the readily exchangeable $\mathrm{Cu}^{2+}$ in a cell is estimated to be $\gg 1000$-fold lower than that of $\mathrm{Zn}^{2+} \cdot{ }^{29}$ Theoretically, by conjugating CA mutants on the nanogels, the sensing selectivity can be tailored.

Surface conjugation of biologics onto nanoparticles may also lead to further applications. For example, studies have found that, in a biological environment, nanoparticles are covered by an adsorbed protein layer, or "protein corona". The protein corona of the nanoparticles is what the cells actually "see" and interact with. ${ }^{56}$ Therefore, by modifying the nanoparticle surface with proteins (ie, albumin), the nanoparticles may be "disguised" as proteins in a living system, and thus their potential vulnerability or toxicity can be reduced, and their half-life increased. ${ }^{57}$ This would be similar to the use of PEG (polyethylene glycol) for covering the surface of hydrogel nanoparticles for biomedical applications. ${ }^{22}$

In summary, the two methods presented for the nanogel embedding and protection of "soft" biological enzymes each have their advantages and limitations. In addition, the PAAm nanomatrix (nanogel) and its manufacturing process have shown excellent "engineer-ability".

\section{Acknowledgments}

This work was supported by National Institute of Health grants R33CA125297 (RK), R01CA250499 (RK) and R01GM40602 (CAF), the National Science Foundation grant DMR 0455330 (RK), the National Natural Science Foundation of China 81660508 (GN), the Guangxi Science and Technology Key Research Project Guike-AB17195076 (GN) and Guike-AB16380153 (GN), the Guangxi Innovation Driven Development Major Project GuikeAA20302013 (GN), and Nanning Scientific Research and Technology Development Plan Project RC20200001 (GN). We acknowledge the Electron Microbeam Analysis Laboratory (EMAL) at the University of Michigan for their technical support in SEM imaging.

\section{Disclosure}

The authors report no conflicts of interest in this work.

\section{References}

1. Jose J, Thomas S, ThaKur VK. Nano Hydrogels: Physico-Chemical Properties and Recent Advances in Structural Designing. Singapore: Springer; 2021.
2. Joshy KS, Thomas S, ThaKur VK. Nanoparticles for Drug Delivery. Singapore: Springer; 2021.

3. Mohanty F, Swain SK. Nano silver embedded starch hybrid graphene oxide sandwiched poly(ethylmethacrylate) for packaging application. Nano Struct Nano Objects. 2019;18:100300. doi:10.1016/j.nanoso.20 19.100300

4. Adhikari J, Perwez MS, Das A, Saha P. Development of hydroxyapatite reinforced alginate-chitosan based printable biomaterial-ink. Nano Struct Nano Objects. 2021;25:100630. doi:10.1016/j.nanoso. 2020.100630

5. Nguyen $\mathrm{HH}$, Lee SH, Lee UJ, Fermin CD, Kim M. Immobilized enzymes in biosensor applications. Materials. 2019;12:121-154. doi:10.3390/ma12010121

6. Ansari SA, Husain Q. Potential applications of enzymes immobilized on/in nano materials: a review. Biotechnol Adv. 2012;30:512-523. doi:10.1016/j.biotechadv.2011.09.005

7. Pagels RF, Prud'homme RK. Polymeric nanoparticles and microparticles for the delivery of peptides, biologics, and soluble therapeutics. J Control Release. 2015;219:519-535. doi:10.1016/j.jconrel.2015.09.001

8. Li Y, Wang F, Cui H. Peptide-based supramolecular hydrogels for delivery of biologics. Bioeng Transl Med. 2016;1:306-322. doi: $10.1002 / \mathrm{btm} 2.10041$

9. Wong LS, Khan F, Micklefield J. Selective covalent protein immobilization: strategies and applications. Chem Rev. 2009;109:4025-4053. doi: $10.1021 / \mathrm{cr} 8004668$

10. Fisher SA, Baker AEG, Shoichet MS. Designing peptide and protein modified hydrogels: selecting the optimal conjugation strategy. $\mathrm{J} \mathrm{Am}$ Chem Soc. 2017;139(22):7416-7427. doi:10.1021/jacs.7b00513

11. Li J, Kataoka K. Chemo-physical strategies to advance the in vivo functionality of targeted nanomedicine: the next generation. $J \mathrm{Am}$ Chem Soc. 2021;143:538-559.

12. Hwang ET, Gu MB. Enzyme stabilization by nano/microsized hybrid materials. Eng Life Sci. 2013;13:49-61. doi:10.1002/ elsc. 201100225

13. Pérez-Luna VH, González-Reynoso O. Encapsulation of biological agents in hydrogels for therapeutic applications. Gels. 2018;4:61-90. doi:10.3390/gels4030061

14. Pollak A, Blumenfeld H, Wax M, Baughn RL, Whitesides GM. Enzyme immobilization by condensation copolymerization into cross-linked polyacrylamide gels. J Am Chem Soc. 1980;10 2:6324-6336. doi:10.1021/ja00540a026

15. Rosenzweig Z, Kopelman R. Analytical properties and sensor size effects of a micrometer-sized optical fiber glucose biosensor. Anal Chem. 1996;68:1408-1413. doi:10.1021/ac950864g

16. Bu H, Mikkelsen SR, English AM. NAD(P)H sensors based on enzyme entrapment in ferrocene-containing polyacrylamide-based redox gels. Anal Chem. 1998;70:4320-4325. doi:10.1021/ ac9802877

17. Xu H, Aylott JW, Kopelman R. Fluorescent nano-PEBBLE sensors designed for intracellular glucose imaging. Analyst. 2002;127: 1471-1477. doi:10.1039/b202782h

18. Sumner JP, Westerberg N, Stoddard AK, Fierke CA, Kopelman R. Cu + and $\mathrm{Cu} 2+$ sensitive PEBBLE fluorescent nanosensors using DsRed as the recognition element. Sens Actuators B. 2005;113:760-767. doi:10.1016/j.snb.2005.07.028

19. Poulsen K, Scharff-Poulsen AM, Olsen LF. Horseradish peroxidase embedded in polyacrylamide nanoparticles enables optical detection of reactive oxygen species. Anal Biochem. 2007;366:29-36. doi:10.1016/j.ab.2007.04.004

20. Sun H, Scharff-Poulsen AM, Gu H, et al. Phosphate sensing by fluorescent reporter proteins embedded in polyacrylamide nanoparticles. ACS Nano. 2008;2:19-24. doi:10.1021/nn700166x

21. Yoon HK, Ray A, Koo Lee Y, Kim G, Wang X, Kopelman R. Polymerprotein hydrogel nanomatrix for stabilization of indocyanine green towards targeted fluorescence and photoacoustic bio-imaging. J Mater Chem. 2013;B1:5611-5619. doi:10.1039/c3tb21060j 
22. Koo Lee Y, Smith R, Kopelman R. Nanoparticle PEBBLE sensors in live cells and in vivo. Annu Rev Anal Chem. 2009;2:57-76. doi:10.1146/annurev.anchem.1.031207.112823

23. Bobone S, Miele E, Cerroni B, et al. Liposome-templated hydrogel nanoparticles as vehicles for enzyme-based therapies. Langmuir. 2015;31:7572-7580. doi:10.1021/acs.langmuir.5b01442

24. Krishnamurthy VM, Kaufman GK, Urbach AR, et al. Carbonic anhydrase as a model for biophysical and physical-organic studies of proteins and protein-ligand binding. Chem Rev. 2008;108:946-1051.

25. Kiefer LL, Paterno SA, Fierke CA. Hydrogen bond network in the metal binding site of carbonic anhydrase enhances zinc affinity and catalytic efficiency. J Am Chem Soc. 1995;117:6831-6837. doi:10. 1021/ja00131a004

26. Fierke CA, Thompson RB. Fluorescence-based biosensing of zinc using carbonic anhydrase. BioMetals. 2001;14(3/4):205-222. doi:10.1023/A:1012980628412

27. Bozym RA, Thompson RB, Stoddard AK, Fierke CA. Measuring picomolar intracellular exchangeable zinc in PC-12 cells using a ratiometric fluorescence biosensor. ACS Chem Biol. 2006;1:103-111. doi:10.1021/cb500043a

28. Bozym R, Hurst TK, Westerberg N, et al. Determination of zinc using carbonic anhydrase-based fluorescence biosensors. Methods Enzymol. 2008;450:287-309.

29. Hurst TK, Wang D, Thompson RB, Fierke CA. Carbonic anhydrase II-based metal ion sensing: advances and new perspectives. Biochim Biophys Acta. 2010;1804:393-403. doi:10.1016/j.bbapap.2009.09.031

30. Wang D, Hurst TK, Thompson RB, Fierke CA. Genetically encoded ratiometric biosensors to measure intracellular exchangeable zinc in E. coli. J Biomed Opt. 2011;16(8):087011. doi:10.1117/1.3613926

31. Thompson RB, Fierke CA. Measuring and imaging metal ions with fluorescence-based biosensors: speciation, selectivity, kinetics, and other issues. Methods Enzymol. 2017;589:281-299.

32. Vinkenborg JL, Nicolson TJ, Bellomo EA, Koay MS, Rutter GA, Merkx M. Genetically encoded FRET sensors to monitor intracellular $\mathrm{Zn}^{2+}$ homeostasis. Nat Methods. 2009;6:737-740. doi:10.1038/nmeth. 1368

33. Qin Y, Dittmer PJ, Park JG, Jansen KB, Palmer AE. Measuring steady-state and dynamic endoplasmic reticulum and Golgi $\mathrm{Zn}^{2+}$ with genetically encoded sensors. Proc Natl Acad Sci USA. 2011;108:7351-7356. doi:10.1073/pnas.1015686108

34. Qin Y, Miranda JG, Stoddard CI, Dean KM, Galati DF, Palmer AE. Direct comparison of a genetically encoded sensor and small molecule indicator: implications for quantification of cytosolic $\mathrm{Zn}^{2+}$. ACS Chem Biol. 2013;8:2366-2371. doi:10.1021/cb4003859

35. Bose H, Satyanarayana T. Microbial carbonic anhydrases in biomimetic carbon sequestration for mitigating global warming: prospects and perspectives. Front Microbiol. 2017;8:1615-1634. doi:10.3389/ fmicb.2017.01615

36. Moriyama J, Yoshimoto M. Efficient entrapment of carbonic anhydrase in alginate hydrogels using liposomes for continuous-flow catalytic reactions. ACS Omega. 2021;6:6368-6378. doi:10.1021/ acsomega.0c06299

37. Wen H, Zhang L, Du Y, et al. Bimetal based inorganic-carbonic anhydrase hybrid hydrogel membrane for $\mathrm{CO}_{2}$ capture. J CO2 Util. 2020;39:101171-101179. doi:10.1016/j.jcou.2020.101171

38. Ren S, Li C, Tan Z, Hou Y, Jia S, Cui J. Carbonic anhydrase@ZIF-8 hydrogel composite membrane with improved recycling and stability for efficient $\mathrm{CO}_{2}$ capture. J Agric Food Chem. 2019;67:3372-3379. doi:10.1021/acs.jafc.8b06182

39. Kim CS, Yang YJ, Bahn SY, Cha HJ. A bioinspired dual-crosslinked tough silk protein hydrogel as a protective biocatalytic matrix for carbon sequestration. NPG Asia Mater. 2017;9:e391. doi:10.1038/ am.2017.71
40. Zhang Y, Zhi T, Zhang L, Huang H, Chen H. Immobilization of carbonic anhydrase by embedding and covalent coupling into nanocomposite hydrogel containing hydrotalcite. Polymer. 2009;50: 5693-5700. doi:10.1016/j.polymer.2009.09.067

41. Zhang Y, Fan L, Zhi T, Zhang L, Huang H, Chen H. Synthesis and characterization of poly(acrylic acid-coacrylamide)/hydrotalcite nanocomposite hydrogels for carbonic anhydrase immobilization. J Polym Sci a Polym Chem. 2009;47:3232-3240. doi:10.1002/pola.23367

42. Sulfhydryl-reactive crosslinker chemistry. Available from: https:// www.thermofisher.com/. Accessed September 8, 2021.

43. Kunieda H, Shinoda K. Evaluation of the hydrophile-lipophile balance (HLB) of nonionic surfactants. I. Multisurfactant systems. J Colloid Interface Sci. 1985;1:107-121. doi:10.1016/0021-9797(85)90154-7

44. Griffin WC. Classification of surface-active agents by "HLB". J Soc Cosmet Chem. 1949;1:311-326.

45. Anderson J, Byrne T, Woelfel KJ, Meany JE. The hydrolysis of p-nitrophenyl acetate: a versatile reaction to study enzyme kinetics. J Chem Educ. 1994;71:715-718. doi:10.1021/ed071p715

46. Pierce ${ }^{\mathrm{TM}}$ coomassie plus (Bradford) assay kit. Available from: https:// www.thermofisher.com/. Accessed September 8, 2021.

47. Iyer R, Barrese AA, Parakh S, Parker CN, Tripp BC. Inhibition profiling of human carbonic anhydrase II by high-throughput screening of structurally diverse, biologically active compounds. J Biomol Screen. 2006;11:782-791. doi:10.1177/1087057106289403

48. WEBMAXC. Available from: http://www.stanford.edu/ cpatton/web maxc/webmaxcS.htm. Accessed September 8, 2021.

49. Otero C, Robledo L, Del Val Mi. Two alternatives: lipase and/or microcapsule engineering to improve the activity and stability of Pseudomonas sp. and Candida rugosa lipases in anionic micelles. Prog Colloid Polym Sci. 1996;100:296-300.

50. Shome A, Roy S, Das PK. Nonionic surfactants: a key to enhance the enzyme activity at cationic reverse micellar interface. Langmuir. 2007;23:4130-4136. doi:10.1021/la062804j

51. Gu Z, Biswas A, Zhao M, Tang Y. Tailoring nanocarriers for intracellular protein delivery. Chem Soc Rev. 2011;40:3638-3655. doi: $10.1039 / \mathrm{c} 0 \mathrm{cs} 00227 \mathrm{e}$

52. Jing G, Pan F, Lv B, Zhou Z. Immobilization of carbonic anhydrase on epoxy-functionalized magnetic polymer microspheres for $\mathrm{CO}_{2}$ capture. Process Biochem. 2015;50:2234-2241. doi:10.1016/j. procbio.2015.09.015

53. De M, Rana S, Akpinar H, et al. Sensing of proteins in human serum using conjugates of nanoparticles and green fluorescent protein. Nature Chem. 2009;1:461-465. doi:10.1038/nchem.334

54. Liu Q, Chiu A, Wang LH, et al. Zwitterionically modified alginates mitigate cellular overgrowth for cell encapsulation. Nat Commun 2019;10:5262-5275. doi:10.1038/s41467-019-13238-7

55. Kremer M, Pothmann E, Bossier T, et al. Pore-size distributions of cationic polyacrylamide hydrogels varying in initial monomer concentration and cross-linker/monomer ratio. Macromolecules. 1994;27:2965-2973. doi:10.1021/ma00089a012

56. Lynch KA, Dawson KA. Protein-nanoparticle interactions. Nano Today. 2008;3:40-47. doi:10.1016/S1748-0132(08)70014-8

57. Ge C, Du J, Zhao L, et al. Binding of blood proteins to carbon nanotubes reduces cytotoxicity. Proc Natl Acad Sci. 2011;108:16968-16973. doi:10.1073/pnas.1105270108

58. Si D. PEBBLE Nanosensors for Intracellular Imaging and Analysis of Free Calcium and Zinc [PhD thesis]. Ann Arbor: University of Michigan; 2011:60-119.

59. Thompson RB, Maliwal BP, Zeng HH. Zinc biosensing with multiphoton excitation using carbonic anhydrase and improved fluorophores. J Biomed Opt. 2000;5(1):17-22. 


\section{Publish your work in this journal}

The International Journal of Nanomedicine is an international, peerreviewed journal focusing on the application of nanotechnology in diagnostics, therapeutics, and drug delivery systems throughout the biomedical field. This journal is indexed on PubMed Central, MedLine, CAS, SciSearch ${ }^{\circledR}$, Current Contents ${ }^{\circledR} /$ Clinical Medicine,
Journal Citation Reports/Science Edition, EMBase, Scopus and the Elsevier Bibliographic databases. The manuscript management system is completely online and includes a very quick and fair peer-review system, which is all easy to use. Visit http://www.dovepress.com testimonials.php to read real quotes from published authors. 